Elsevier required licence: (C) <2019>. This manuscript version is made available under the CC-BY-NCND 4.0 license http://creativecommons.org/licenses/by-nc-nd/4.0/

The definitive publisher version is available online at

[https://www.sciencedirect.com/science/article/pii/S1385894719309350?via\%3Dihub] 


\title{
Reuse of municipal wastewater via membrane capacitive deionization using ion-selective polymer- coated carbon electrodes in pilot-scale
}

David Inhyuk Kim a,b Pema Dorji ${ }^{\mathrm{a}}$, Gimun Gwak ${ }^{\mathrm{c}}$, Sherub Phuntsho ${ }^{\mathrm{a}}$, Seungkwan Hong ${ }^{\mathrm{b}, *}$, and Hokyong Shon ${ }^{\mathrm{a}, *}$

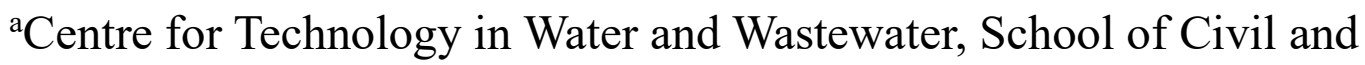
Environmental Engineering, University of Technology Sydney (UTS), 15 Broadway, NSW 2007, Australia

${ }^{b}$ School of Civil, Environmental \& Architectural Engineering, Korea University, 145, Anam-ro, Seongbuk-Gu, Seoul, 02841, Republic of Korea ${ }^{\mathrm{c}}$ Center for Water Resource Cycle Research, Korea Institute of Science and Technology, 5, Hwarang-ro 14-gil, Seongbuk-gu, Seoul, 02792, Republic of Korea

\footnotetext{
*Corresponding authors. E-mail addresses: hokyong.shon-1@uts.edu.au (H.K. Shon), skhong21@korea.ac.kr (S. Hong).
}

\begin{abstract}
This study investigated membrane capacitive deionization (MCDI) at a pilot-scale using ionselective polymer-coated carbon electrodes for wastewater reuse. Several issues have been addressed to verify the suitability of MCDI for wastewater reclamation: electrosorption
\end{abstract}


performance, removal efficiency and selectivity of ions present in wastewater, optimization of operating conditions, and performance degradation in long-term caused by the accumulation of organic contaminants. The coated electrodes had better adsorption capacities and charge efficiencies than the conventional MCDI system, which was attributed to their low electrical resistance induced by the thin coated layer. The pilot-scale MCDI test cell involved 50 pairs of anion- and cation-selective electrodes and achieved good removal efficiency of ions from the wastewater effluent, particularly for problematic charged impurities, such as nitrate $\left(\mathrm{NO}_{3}{ }^{-}\right.$) (up to $91.08 \%$ of $\mathrm{NO}_{3}{ }^{-}$was removed). Increasing the flow rate and reducing the applied potential were shown to be efficient for achieving better water quality by enhancing the $\mathrm{NO}_{3}{ }^{-}$selectivity. Last, the $15 \mathrm{~d}$ operation showed good reproducibility in electrosorption and regeneration for the coated electrodes, despite the fact that high concentrations of organics were contained in the wastewater feed solution $(12.4$ $\mathrm{mg} / \mathrm{L}$ of dissolved organic carbon).

Keywords: Membrane capacitive deionization; Ion-selective carbon electrode; Wastewater reuse; Ion selectivity; Nitrate removal 


\section{Introduction}

The depletion of freshwater resources has been attributed to the large demands for water due to rising population and global urbanization. Accordingly, the world is projected to face a $40 \%$ global water deficit by 2030 [1]. Given the worldwide depletion of the available water resources, wastewater, which has been perceived as an undervalued resource, has now become a must-have component that needs to be properly managed to enhance the economic sustainability [2]. The increased demand for water resources is now driving the need for reclaiming wastewater resources to alleviate the impact of some of the imposed pressures attributed to this growing demand. Therefore, water reuse is gaining momentum as a reliable alternative source of freshwater [3]. The reuse of wastewater is expected to elicit significant economic and environmental benefits by increasing water availability and by reducing the over-abstraction of freshwater, thereby diminishing the volume of discharged wastewater, and ensuring the quality of wastewater.

The United Nations established the 2030 Agenda for Sustainable Development with a set of 17 sustainable development goals (SDGs) [4]. The establishment of SDG 6, namely "Ensure availability and sustainable management of water and sanitation for all," reflects the critical interests based on water scarcity and the needs of procuring water resources. Recycling, reusing, and recovering wastewater resources are expected to alleviate water stress and offer environmental and economic benefits. Additionally, wastewater is an important source of recoverable nutrients and other valuable materials which can be recovered and reutilized [5].

However, the management of wastewater resources has been constrained by the current practices of wastewater treatment, which remain at a basic level and only satisfying the regulations for water discharge into natural streams. The quality of wastewater effluent treated by conventional practices needs to be refined by advanced water treatment technologies. Given that only a small fraction of wastewater effluent undergoes advanced treatment processes, the installation of tertiary water treatment facilities to obtain high quality reclaimed water is crucial $[6,7]$. In addition, the strict regulatory standards for wastewater effluent are mandating the water industry to develop new technologies that are suitable for sustainable wastewater reuse. Specifically, domestic and municipal wastewaters are characterized by their increased loads of nitrogen and phosphorus, which are associated with 
limited removal and economically unfeasible processes based on the adoption of conventional treatment technologies, such as biological treatments that ultimately cause hightoxicity levels, oxygen depletion, and eutrophication issues [8].

Capacitive deionization (CDI), an electrostatically driven process, has been acknowledged as an energy-efficient and eco-sustainable technology for removing charged species from saline water resources because it does not require any chemicals or hydraulic/thermal energy [9]. A typical CDI system consists of two electrodes at which an electrical potential is applied. Consequently, the charged ions in the feed solution are attracted within the electrical double layer (EDL) formed between the electrode and feed solution interface. This process is exceptionally energy-efficient compared to other possible desalting technologies for desalinating low-concentration salt water below 5000 ppm [10] because it readily removes relatively few salts from low-saline water compared to the removal of water molecules through the extensively used technique of reverse osmosis [11]. Hence, this technology is expected to have strong potential applicability in advanced wastewater treatment processes attaining enhanced removal of salinity, especially for problematic species, such as nitrates, to obtain reclaimed water [12].

Several studies on CDI for reusing municipal wastewater have been explored thus far as means of removing charged impurities, including high loads of nitrate $\left(\mathrm{NO}_{3}{ }^{-}\right)$and phosphate, which must be removed as they pose a risk to human health. Garcia-Quismondo et al. (2016) provided a comprehensive look at CDI demonstrating its environmental and socio-economic benefits as a technology for wastewater reclamation [13]. The effects of the operational conditions and feed solution chemistry on the electrosorption performance of adjusting the sodium chloride $(\mathrm{NaCl})$ concentration to match it with the ionic concentration of wastewater have been investigated [14]. The degraded performance of the fouled electrode after longer operations in CDI was revealed to be caused by the physically and electrochemically adsorbed organic matters, such as humic- and protein-like substances, and was wellrecovered by implementing proper fresh water flushing and chemical cleaning strategies [15]. Membrane CDI (MCDI) attained better desalination rates than those of typical CDI in wastewater treatment with higher charge efficiencies $[14,16]$, whereas flow electrode CDI was used to conduct simultaneous wastewater reclamation and ammonia recovery during continuous operation [17]. Integrating the electrosorption process with microbial fuel cells as the prior stage by applying an overpotential on the system to generate chlorine were initiated 
as a method of overcoming the weak organic removal capability of CDI [18]. Palko et al. (2018) suggested a hybrid system of CDI where no potential was needed for adsorption to the electrode and the captured ions were consequently expelled through capacitive regeneration [19].

However, the majority of the studies on CDI for the advanced treatment and reuse of wastewater remained in theory and lab-scale investigations. The assessment of MCDI for its application in wastewater reuse is necessary to understand its fluctuating performance owing to the complex nature of the characteristics of real municipal wastewater inflow and operating conditions of a scaled-up system. The selectivity of the charged species that are harmful to human body and their total removal from wastewater under different operating conditions using real wastewater must be probed through a pilot-scale demonstration.

This study explored MCDI, which is considered one of the most efficient systems in practice, for wastewater reclamation at a pilot-scale using real wastewater effluent. The main goal in this work was to demonstrate the suitability of the MCDI process for practical wastewater reuse. We used carbon electrodes coated with a thin anion- or cation-exchange polymer layer that acted as an ion-exchange layer in the MCDI instead of using separate ionexchange membranes (IEMs) for inhibiting the electrosorption of the counter-ions during electrode regeneration, which was expected to induce better electrosorption efficiencies and higher packing densities for the MCDI module. The performance of the coated carbon electrodes was first evaluated at a lab-scale under different flow rates and applied potentials (i.e., adsorption capacity and charge efficiency). The pilot-scale unit used an MCDI module that involved 50 pairs of anion/cation selective electrodes, which was employed to desalinate the charged species from the wastewater effluent. The operating conditions were then optimized to ensure high total ion removal and to enhance the selectivity of problematically charged species, such as nitrates. Last, the electrosorption/regeneration stages were repeatedly run for 15 consecutive days to examine the long-term sustainability of the pilot system, and the findings were then utilized to discuss improvements in this process for real use in wastewater reclamation.

\section{Materials and methods}

2.1. MCDI module consisting of activated carbon electrodes coated by ion-selective polymers 
The activated carbon electrodes were coated by cation- and anion-selective polymers containing a functional group with an ion-exchange capacity, and were provided by Siontech Co. (Republic of Korea). The carbon electrodes consisted of a graphite body sheet coated with a carbon slurry blended with activated carbon $\mathrm{P}-60$ and polyvinylidene fluoride obtained from Kuraray Chemical Co. (Japan) and Inner Mongolia 3F-Wanhao Fluorine Chemical Co. Ltd. (China), respectively [20]. Both sides of each electrode were then coated by ion-selective solutions using an automatic casting machine, thereby forming a thin polymer layer that acted as an IEM. Thus, no separate IEM was needed for inhibiting the sorption of the counter-ions during electrode regeneration in our MCDI system. The dimensions of each activated carbon electrode were $10 \mathrm{~L} \times 10 \mathrm{~W} \mathrm{~cm}^{2}$, and the total carbon mass covering the graphite body was $0.8 \mathrm{~g}$.

Fifty pairs of the coated electrodes were stacked in an acrylic rectangular MCDI module used in the pilot-scale unit. The cation- and anion-selective electrodes were alternately inserted in the module. All the electrodes were separated by an electrically nonconductive nylon mesh spacer, thereby ensuring the availability of space for water flow and preventing short-circuiting. The feed solution that passed through the MCDI system was entirely in contact with the carbon electrodes by punching a hole with a diameter of $1 \mathrm{~cm}$ in the center of the electrodes and nylon spacers. The graphite bodies of each cation- and anion-selective electrode were connected by a conductive copper pole to let the electrical energy pass through the system.

\subsection{Lab-scale MCDI setup and experimental protocol}

The lab-scale MCDI tests were performed using a flow-through unit as described in our previous work (Fig. 1(a)) [21]. A pair of cation- and anion-selective electrodes was symmetrically inserted within the test cell, and a non-conductive spacer was placed between these two electrodes. The feed water was completely in contact with the carbon electrodes by punching a $1 \mathrm{~cm}$ diameter sized hole in the center of the carbon electrodes and nylon spacer. The feed solution was fed throughout the unit using a peristaltic pump made by Cole-Palmer (USA). An electrical potential was supplied to the electrodes by a potentiostat, WPG-100 (WonATech Co., Republic of Korea). Stabilization prior to the experiments was conducted by flushing the feed solution through the system under single-pass at zero voltage until the 
conductivity and $\mathrm{pH}$ of the permeate solution were the same as those of the influent.

(a)

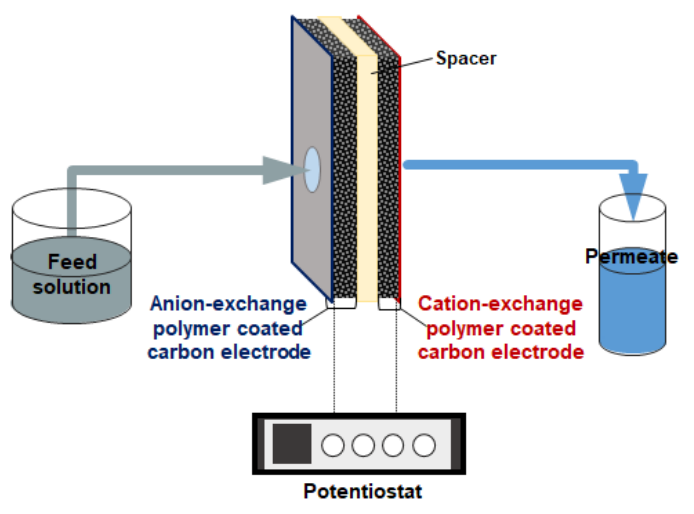

(b)

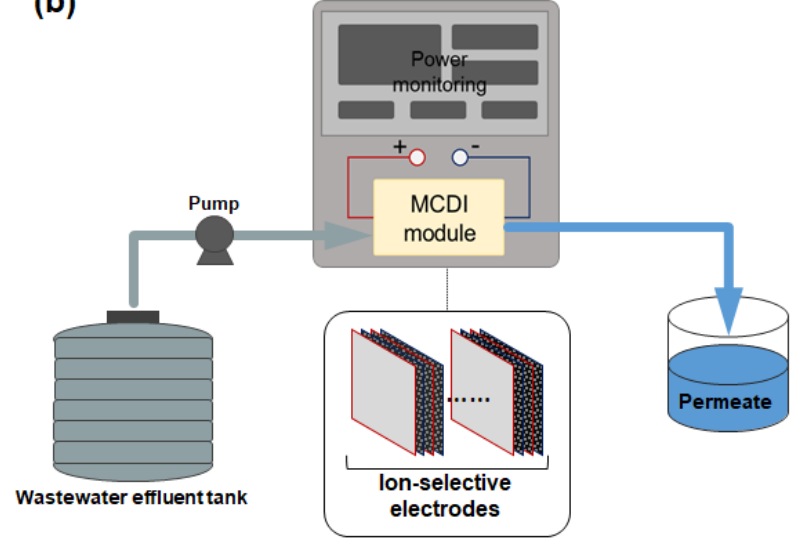

FIGURE 1. Schematic diagram of the (a) lab- and (b) pilot-scale MCDI test units using ionselective electrodes for wastewater reuse.

Single-pass mode experiments were performed to evaluate the adsorption capacity and charge efficiency of the cation/anion-selective electrodes. The feed solution was $10 \mathrm{mM}$ of $\mathrm{NaCl}$, whereas the adjusted flow rate and applied potential varied from 10 to $40 \mathrm{~mL} / \mathrm{min}$ and 0.6 to $1.2 \mathrm{~V}$, respectively. The conductivity data of the permeate solution were recorded on an electrical conductivity meter (Hach, USA) to calculate the adsorption capacity of the electrode. All the tests were run in duplicate at $20^{\circ} \mathrm{C}$.

\subsection{Configuration of the pilot-scale MCDI unit}

A single-pass pilot-scale MCDI system was installed at a decentralized wastewater treatment plant located in Sydney, Australia (Fig. 1(b)). The wastewater effluent from the treatment plant was pumped out through a $10 \mu \mathrm{m}$ pre-filter followed by the MCDI module with the use of a high-pressure pump (Walrus Pump Co., Taiwan). The effluent water after adsorption and desorption of ions ( 2 min for each), which was charged by a direct current power supply, was then separately collected from the permeate and concentrate line. The voltage and current loads on the module were monitored. Electrical conductivity, temperature, and $\mathrm{pH}$ in the inlet from the cell and in the permeate and concentrate lines were 
measured using in-line probes, and the data were saved on a data logger. The hydraulic pressure drop along the electrode module was also monitored by placing pressure meters in the inlet and outlet. The applied potential on the module in this study ranged from $1.2-1.5 \mathrm{~V}$, whereas the flow rate was at $0.5-2.5 \mathrm{~L} / \mathrm{min}$. Prior to the run of each test, the system was stabilized by flushing the wastewater throughout the module at a desired applied voltage with at least five electrosorption and regeneration cycles.

\subsection{Measurement of water quality}

The cationic compositions of the raw and processed wastewater samples, such as sodium $\left(\mathrm{Na}^{+}\right)$, potassium $\left(\mathrm{K}^{+}\right)$, calcium $\left(\mathrm{Ca}^{2+}\right)$, and magnesium $\left(\mathrm{Mg}^{2+}\right)$, were quantified using a microwave plasma atomic emission spectrometer (MP-AES), (4100 MP-AES, Agilent Technologies, USA), while a UV/VIS spectrophotometer (Spectroquant NOVA 60, SigmaAldrich, USA) was used to measure ammonium $\left(\mathrm{NH}_{4}{ }^{+}\right)$with an $\mathrm{NH}_{4}{ }^{+}$photometric test kit (Merck Millipore, United States SA). The anionic species, such as $\mathrm{NO}_{3}{ }^{-}$, nitrite $\left(\mathrm{NO}_{2}{ }^{-}\right)$, chloride $\left(\mathrm{Cl}^{-}\right)$, sulfate $\left(\mathrm{SO}_{4}{ }^{2-}\right)$, and ortho-phosphate $\left(\mathrm{PO}_{4}{ }^{3-}\right)$, were measured using ionic chromatography (IC), (IC Thermo Fisher Scientific, Australia). Total organic carbon (TOC) values of the wastewater and permeate were measured using a multi N/C 3100 TOC analyzer (Analytik Jena, Germany). The solution samples were diluted properly and filtered using a $0.45 \mu \mathrm{m}$ filter (Merck Millipore, USA) before they were analyzed by the measurement devices. The calibrations of MP-AES and IC were carried out before the analyses of the samples based on external calibrations with deionized water and standard synthetic solution $(1.25,2.5,5,10$, and $20 \mathrm{mg} / \mathrm{L}$ of each ion in the mixed solution).

The salt adsorption capacity (SAC) of the electrode at time $t$ was calculated using Eq. (1):

$\operatorname{SAC}(\mathrm{mg} / \mathrm{g})=\frac{m_{t}}{m}=\frac{Q \times \int_{0}^{t}\left(C_{0}-C\right) d t \times M}{m}$

where $\mathrm{m}_{\mathrm{t}}$ is the total amount of adsorbed ions at time $t(\mathrm{mg}), m$ is the mass of carbon on the electrode $(\mathrm{g}), Q$ is the volumetric flow rate $(\mathrm{mL} / \mathrm{min}), C_{0}$ is the initial concentration of feed solution $(\mathrm{mmol} / \mathrm{L}), C$ is the concentration of permeate at time $t(\mathrm{mmol} / \mathrm{L})$, and $M$ represents the molar mass of salt $(\mathrm{mg} / \mathrm{mmol})$.

The charge efficiency $\Lambda$, which is the ratio of salt adsorption to applied charge in the MCDI system, can be derived by Eq. (2): 


$$
\Lambda=\frac{\text { total } n \times F \times \int\left(C_{0}-C\right) d t \times Q}{\int I d t \times A}
$$

where $n$ is the number of electrons needed for reduction/oxidation of one charged species, $F$ is the Faraday's number $(96485.3 \mathrm{C} / \mathrm{mol}), I$ is the current density $\left(\mathrm{A} / \mathrm{m}^{2}\right)$, and $A$ represents the effective surface area of the electrode $\left(0.01 \mathrm{~m}^{2}\right)$.

The electrosorption removal efficiency from the wastewater effluent after pilot operation was calculated using Eq. (3):

Removal efficiency $(\%)=\frac{\left(C_{0}-C\right)}{C_{0}} \times 100$

where $C_{0}$ and $C(\mathrm{mg} / \mathrm{L})$ are the initial and permeate concentrations of wastewater, respectively.

The electrosorption selectivity of ion $i$ at time $t$ can be expressed by Eq. (4):

Adsorption selectivity of $\mathrm{i}=\frac{C_{i, t, b}}{C_{t o t a l, t, b}}$

where $\mathrm{C}_{\mathrm{i}, \mathrm{t}, \mathrm{p}}$ denotes the molar concentration of $i$ and $C_{\text {total,t,p}}$ is the total molar concentration in the permeate solution at time $t$. Larger values of the adsorption selectivity imply that the ion $i$ is more preferentially adsorbed from the carbon electrode over other co-existing ions.

\section{Results and discussion}

\subsection{Electrosorption in MCDI using ion-selective carbon electrodes}

The carbon electrodes covered by ion-selective polymer layers provide effective regenerability by screening the attraction of counter-ions during electrode regeneration [14, 22]. Apart from this, the coated electrode was expected to induce a high adsorption capacity owing to the low resistivity of the thin ion-selective polymer-coated layer compared to the placement of a separate thick IEM. The basic electrosorption performance of the ion-selective electrodes was first tested at the lab-scale, and the results were compared with those that employed a typical MCDI configuration, which was carbon electrodes integrated with separate IEMs.

\subsubsection{SEM analysis of the ion-selective carbon electrodes}


The scanning electron microscope (SEM) images of the top views of the cation- and anion-selective electrodes, and the conventionally used activated carbon electrode are shown in Fig. 2. The original carbon electrode consisted of relatively large particles that appeared to have a granular surface (Fig. 2(a)). Unlike that of the raw carbon electrode, the surface of the ion-selective electrodes coated by a $20 \mu \mathrm{m}$ thick cation- or anion-selective polymer layer was apparently smooth, thereby confirming the fact that the carbon surface was completely covered by the polymer solution. In addition, the carbon particles did not detach from the coated surface by hand rubbing, thereby yielding better mechanical strength attributed to the film coating on the surface. From the observation of the SEM images, the smooth surface was expected to mitigate the degradation of the electrode performance caused by the physical adsorption of organic and inorganic contaminants involved in wastewater because it provide less opportunity for the contaminants to be in contact with and be absorbed onto the electrode surface. The mitigation of performance degradation caused by the impurities is explained more in detail in section 3.4.
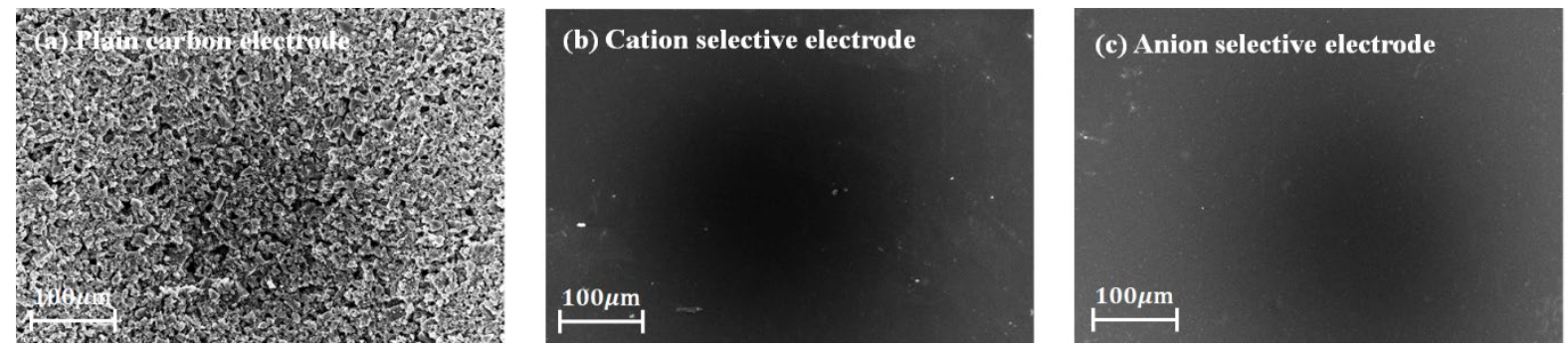

FIGURE 2. SEM images of the surface of (a) the original, (b) cation-selective, and (c) anionselective carbon electrodes.

\subsubsection{Lab-scale performance in MCDI using the selective electrodes}

Fig. 3 presents the SACs in the MCDI using ion-selective carbon electrodes. The results using conventional MCDI consisting of raw carbon electrodes and separate IEMs are also outlined for a better understanding. The SAC reached values up to $0.160,0.188,0.214$, and $0.248 \mathrm{mmol} / \mathrm{g}$ in the ion-selective layer-coated MCDI using the respective voltage values of $0.6,0.8,1.0$, and $1.2 \mathrm{~V}$, whereas the respective SAC values in the conventional MCDI operation were $0.103,0.134,0.181$, and $0.234 \mathrm{mmol} / \mathrm{g}$. This was likely owing to the lower membrane resistance induced by the thinly coated ion-selective layer, which played a role as 
an IEM. The other possibility could have been the low contact resistance between the coating layer and the carbon surface that led to the reduction in energy use and enhanced ion adsorption, whereas high contact resistance was induced by the weak contact adhesion between the separated IEM and the original carbon electrode [23].

The low resistance through the coated layer also facilitated faster ionic transport reaching electrosorption equilibrium after approximately $210 \mathrm{~s}$ compared to that of the IEM in a conventional MCDI system, which attained adsorption equilibrium at approximately $300 \mathrm{~s}$ [24]. However, the amount of adsorbed salts decreased in minute amounts after the ionselective electrode reached saturation, which was probably owing to the co-ion expulsion from the EDL near the pores and the neutral salt discharge from the electrode [25].
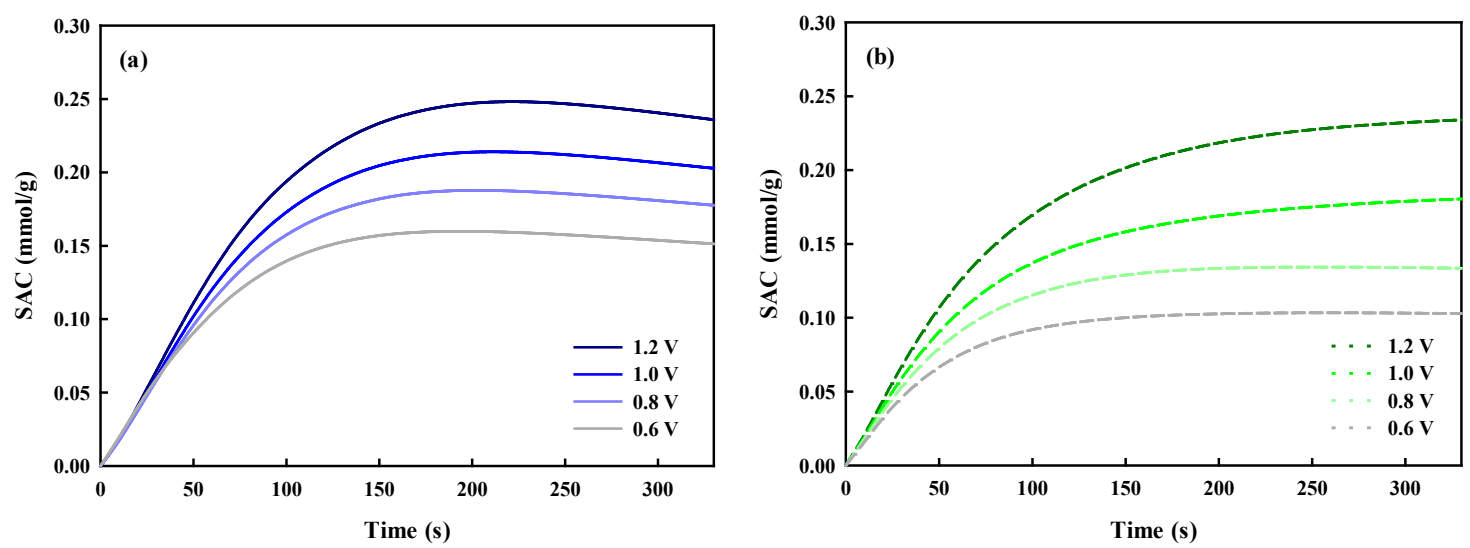

FIGURE 3. SAC of the (a) ion-selective and (b) conventional MCDI systems at different potentials $(0.6-1.2 \mathrm{~V})$.

Charge efficiency is a functional tool to evaluate the energy efficiency of the MCDI system. The average charge efficiency of the ion-selective electrode and the original electrode in the conventional MCDI system was estimated at voltage value of $1.2 \mathrm{~V}$, as shown in Fig. 4 . The average charge efficiency for the conventional MCDI system was $63.6 \%$, while that of the ion-selective electrode was enhanced to $73.3 \%$, which was attributed to the reduced interfacial resistance between the ion-selective polymer layer and carbon electrode caused by their improved contact adhesion [26]. 


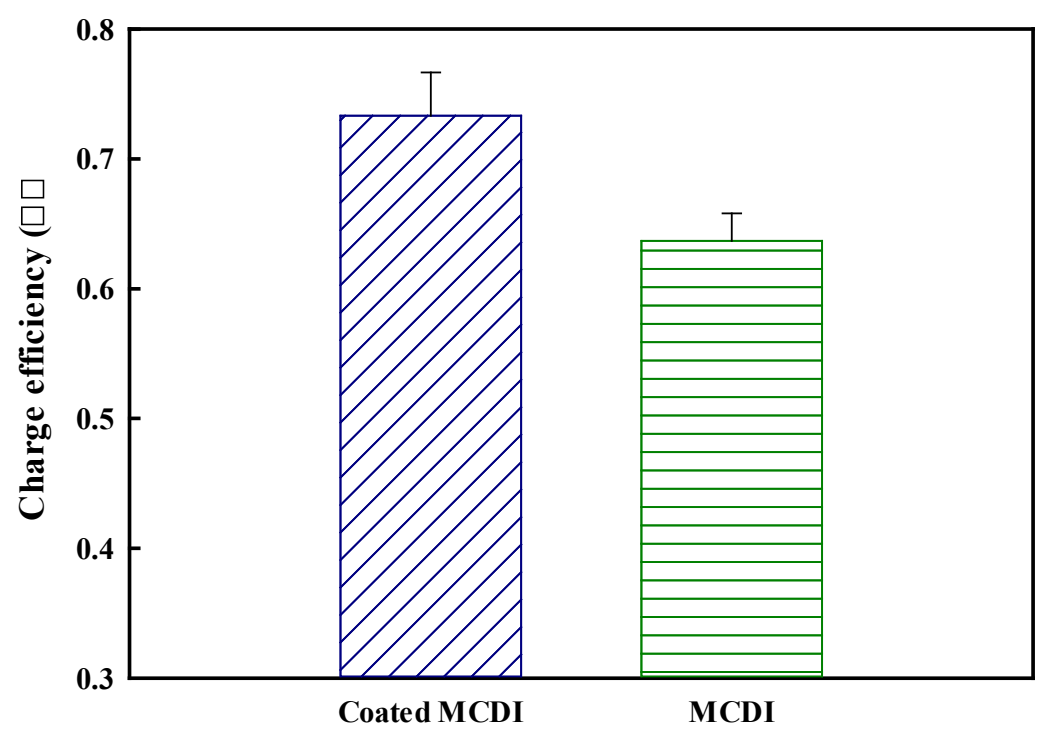

FIGURE 4. Average charge efficiency for ion-selective and conventional MCDI systems at $1.2 \mathrm{~V}$.

\subsection{Removal efficiency of ions in the pilot-scale operation for wastewater reuse}

The competitive removal of ionic species in real municipal wastewater effluent was investigated using a pilot-scale unit under a flow rate of $2 \mathrm{~L} / \mathrm{min}$ and an applied power of 1.2 V. Several studies of preferential electrosorption in (M)CDI revealed that the carbon electrode preferentially trapped the ions present in high concentrations $[27,28]$. To be specific, the ions with higher valence would be more electrochemically adsorbed compared to the lower valence ions on the carbon surface if their respective molar concentration were the same. Last, possessing similar concentrations and the same charge valence allowed smaller hydrated ions with a faster diffusion rate to rapidly migrate toward the carbon surface [29].

TABLE 1 (attached to the last page)

As shown in Table $1, \mathrm{Na}^{+}$was the most adsorbed ion on the cathode, which was owing to its high initial concentrations in the wastewater feed. However, the removal efficiency of $\mathrm{Na}^{+}$ 
in terms of percent removal was the lowest, even though the number of adsorbed $\mathrm{Na}^{+}$ions on the electrode outnumbered that of other cations. Given that $\mathrm{K}^{+}$diffused faster and $\mathrm{Ca}^{2+}$ had stronger electrochemical attraction toward the electrode surface, the portion of their adsorbed ions was relatively higher than that of $\mathrm{Na}^{+}$[29]. Unlike the ion adsorption selectivity in terms of the number of adsorbed ions, which was primarily determined by the initial concentration of the ions (specific selectivity in the expression of $\mathrm{mmol} / \mathrm{mmol}_{\text {total }}$ in Fig. 5(a)), the ion selectivity in terms of removal efficiency was rather governed by the feed solution characteristics, such as the diffusion rate and charge valence (specific selectivity in units of $\% / \%$ total in Fig. 5(a)).

Interestingly, the total amount of removed cations was greater than that of the anions. The asymmetry of the anion and cation removals was likely due to the electrosorption of the negatively charged organic substances present in the wastewater. These results implied that the organics were attracted near the EDL, and the space for the anions to be adsorbed became limited as the electrode was saturated. More specific discussions regarding the removal of organic compounds are provided in section 3.4. Changes in the electrode surface chemistry attributed to Faradaic reactions and the selective electrosorption of $\mathrm{H}^{+}$and $\mathrm{OH}^{-}$may also have accounted for the imbalance in anion and cation removals [30]. However, the likelihood of a significant reaction of carbon oxidation was low owing to the stability of MCDI from the presence of IEMs [31].

The preferential electrosorption sequence of the major anions present in wastewater, in terms of the adsorption capacity, was in the order of $\mathrm{Cl}^{-}>\mathrm{NO}_{3}{ }^{-}>\mathrm{SO}_{4}{ }^{2-}$, as mainly determined by their initial concentrations (Fig. 5(b)). The removal efficiency of the three major ions was in accordance with the order of $\mathrm{NO}_{3}{ }^{-}>\mathrm{Cl}^{-}>\mathrm{SO}_{4}{ }^{2-}$. Unlike the trend in electrosorption of cations from wastewater, the order of removal efficiency was less compliant with the charge valence and diffusion kinetics. In addition, the removal efficiency of $\mathrm{NO}_{3}{ }^{-}$was much higher than that of $\mathrm{Cl}^{-}$, even though their hydrated ionic sizes and diffusion coefficients were similar. The hydrated radii of $\mathrm{Cl}^{-}$and $\mathrm{NO}_{3}{ }^{-}$were $0.332 \mathrm{~nm}$ and $0.335 \mathrm{~nm}$, respectively [32], whereas the diffusion coefficients both near $1.7 \times 10^{-9} \mathrm{~m}^{2} / \mathrm{s}[33,34]$. Several studies attributed the better selectivity of $\mathrm{NO}_{3}{ }^{-}$to its strong hydrophobicity over the other major anions [27, 29], thus, its stronger affinity to the hydrophobic electrode surface $\left(97.86 \pm 0.67^{\circ}\right.$ contact angle) allowed it to replace the $\mathrm{Cl}^{-}$and $\mathrm{SO}_{4}{ }^{2-}$ ions. 
The removal efficiency of divalent $\mathrm{SO}_{4}{ }^{2-}$ was expected to be higher than that of the monovalent ions owing to its affinity to screen the surface charge of the electrode caused by its higher valence. The selectivity of $\mathrm{SO}_{4}{ }^{2-}$, which is the representative divalent anion in wastewater, was controversial in several studies. Li et al. (2016) reported that the activated carbon electrode in conventional CDI accepted more $\mathrm{SO}_{4}{ }^{2-}$ than $\mathrm{NO}_{3}^{-}$primarily owing to the higher electrostatic attraction of $\mathrm{SO}_{4}{ }^{2-}$, which was mainly determined by its higher valence [35]. For MCDI, Tang et al. (2017) and Yeo et al. (2013) both reported that the competitive removal of $\mathrm{SO}_{4}{ }^{2-}$ could be determined as a function of the applied electrical current $[36,37]$. These works observed a higher selectivity for $\mathrm{SO}_{4}{ }^{2-}$ compared to that for $\mathrm{Cl}^{-}$as the applied constant current increased. However, the adsorbed amount of $\mathrm{SO}_{4}{ }^{2-}$ from a mixture solution that consisted of $\mathrm{Cl}^{-}, \mathrm{NO}_{3}{ }^{-}$, and $\mathrm{SO}_{4}{ }^{2-}$ was similar to that of the other ions in a MCDI study conducted by Hassan et al. (2018) [29]. The percent removal of $\mathrm{SO}_{4}{ }^{2-}$ from water obtained from the Colorado River was much lower than that of the other two anions during electrosorption, as reported by Gabelich et al. (2002) [38], despite the fact that the initial concentrations were in the order of $\mathrm{SO}_{4}{ }^{2-} \cong \mathrm{Cl}^{-}>>\mathrm{NO}_{3}{ }^{-}$.

Our results of the order of removal efficiency for both the cations and anions followed the general permselectivity trend through the IEMs. Especially for the anions, their permselectivity through anion-exchange membranes (AEMs) correlated with the Gibbs hydration energy of anions and Hofmeister anion series [39, 40]. The anion permselectivity was dependent on the affinity of the anions to the membrane. In addition, their selectivity was also affected by the change in their mobility through the AEM [39, 40]. As shown in the results (Table 1 and Fig. 5(b)), the preferential adsorption of the major anions, in terms of removal efficiency, in the wastewater was likely determined by the permselectivity trend in IEMs. Furthermore, the change in the order of preferential adsorption of the anions in MCDI with different applied potentials could also be explained by the change in ion mobility through the IEM [41]. As the mobility coefficients of $\mathrm{NO}_{3}{ }^{-}, \mathrm{Cl}^{-}$, and $\mathrm{SO}_{4}{ }^{2-}$ were 7.40, 7.91, and $8.29 \times 10^{-8} \mathrm{~m}^{2} / \mathrm{s} \cdot \mathrm{V}$, respectively, the increased electrical energy applied in the MCDI system may have led to the increased mobility of $\mathrm{SO}_{4}{ }^{2-}$ through the AEM compared to that of $\mathrm{Cl}^{-}$, as shown by Tang et al. (2017) and Yeo et al. (2013) [36, 37]. 

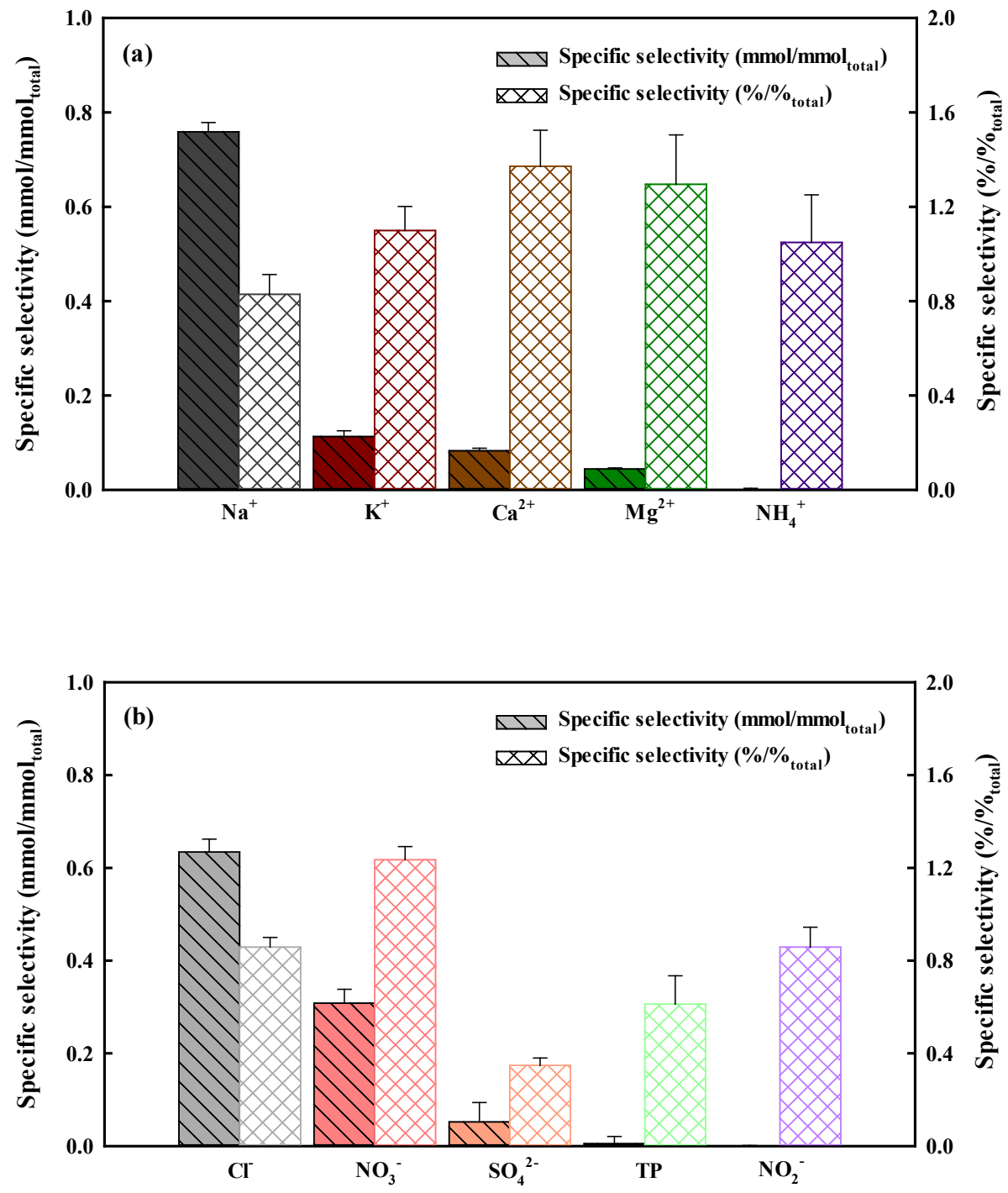

FIGURE 5. Specific selectivities of (a) cations and (b) anions on ion-selective polymercoated electrodes in wastewater. The left axis shows the selectivity derived by the number of adsorbed ions divided by the total number of removed cations or anions. The right axis shows the selectivity derived by the removal efficiency of the ions divided by the average removal efficiency of the total number of ions (61.3\% total removal efficiency).

\subsection{Improvement of the MCDI performance for better water quality}

The influence of the operating conditions in the MCDI system on the electrosorption performance during wastewater reuse was investigated. 


\subsubsection{Effect of electrosorption time on ion selectivity in wastewater effluent}

For the cations, the adsorption rates of $\mathrm{Na}^{+}$and $\mathrm{K}^{+}$dramatically decreased as a function of time, whereas the divalent species $\left(\mathrm{Ca}^{2+}\right.$ and $\left.\mathrm{Mg}^{2+}\right)$ were adsorbed on the electrode at a steady rate for $2 \mathrm{~min}$ (Fig. 6). This was likely owing to the high affinity of the divalent ions on the EDL, which replaced the monovalent ions adsorbed on the surface. Therefore, shorter operation of MCDI led to the better removal of monovalent cations.

Among the anions (Fig. 6(b)), the $\mathrm{NO}_{3}{ }^{-}$concentration in the effluent was maintained at a low level, whereas those of $\mathrm{Cl}^{-}$and $\mathrm{SO}_{4}{ }^{2-}$ increased. This could be explained by the high affinity of $\mathrm{NO}_{3}{ }^{-}$to the carbon electrode owing to its hydrophobicity, as discussed in Section 3.2. Accordingly, this resulted in the substitution of $\mathrm{Cl}^{-}$and $\mathrm{SO}_{4}{ }^{2-}$ by $\mathrm{NO}_{3}{ }^{-}$in longer operations. Therefore, we could expect high and selective removal of $\mathrm{NO}_{3}{ }^{-}$during longer operation, which is one of the most problematic species for the reuse of wastewater.

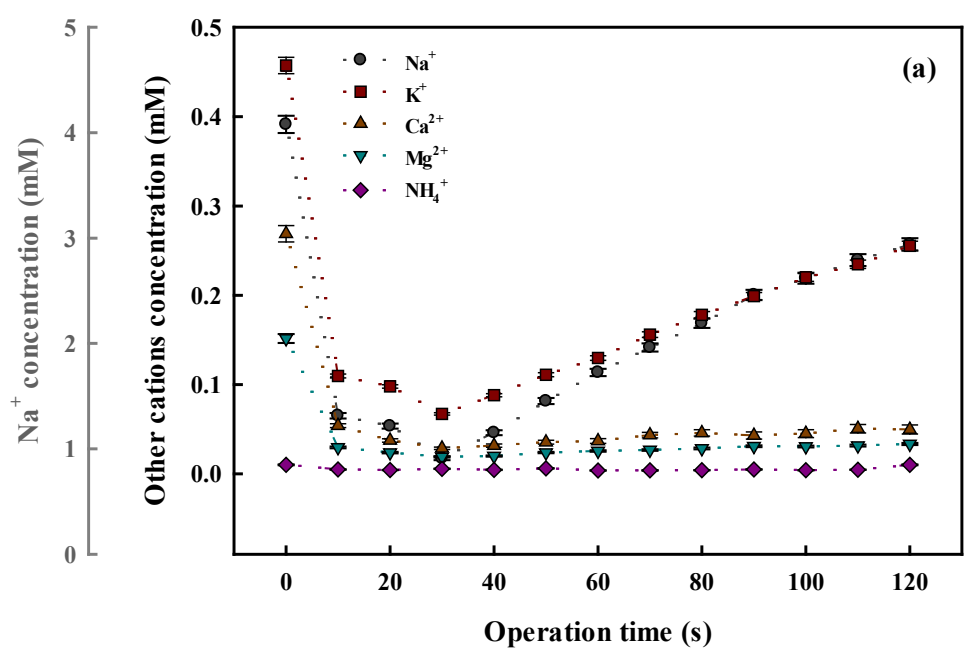




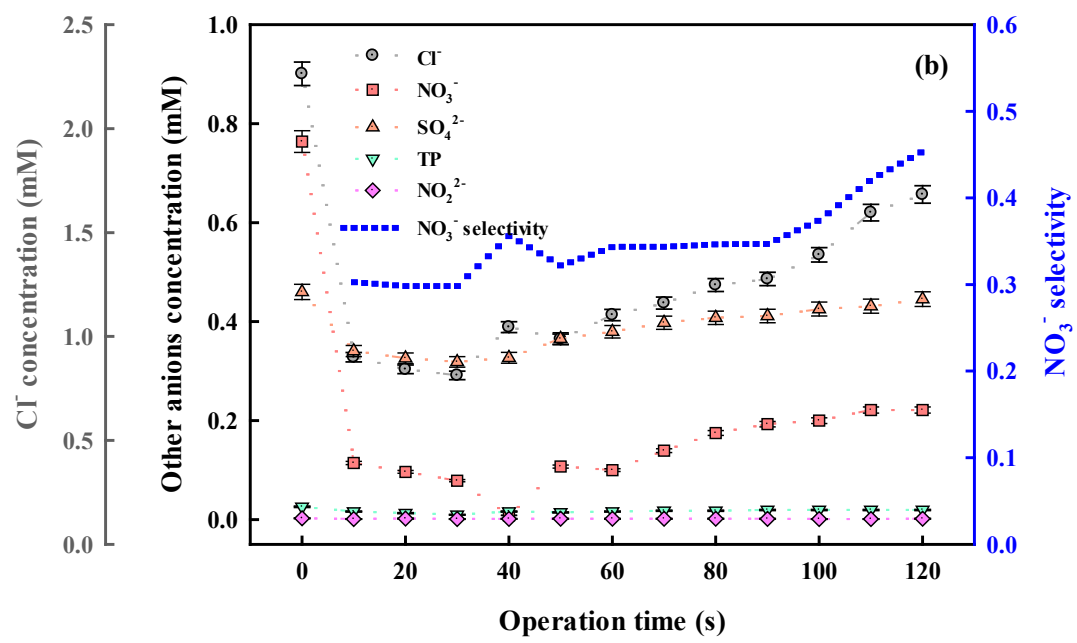

FIGURE 6. Changes in permeate (a) cation and (b) anion concentrations obtained from ionselective MCDI cells during the treatment of wastewater.

\subsubsection{Effect of applied potential and flow rate on selective $\mathrm{NO}_{3}{ }^{-}$removal}

The permeate that passed through the MCDI pilot unit based on a single-pass continuous flow regime was collected during a 2-min period at different flow rates and applied potentials. Fig. 7 shows the variation in the average removal and selectivity of $\mathrm{NO}_{3}{ }^{-}$of the sampled water.
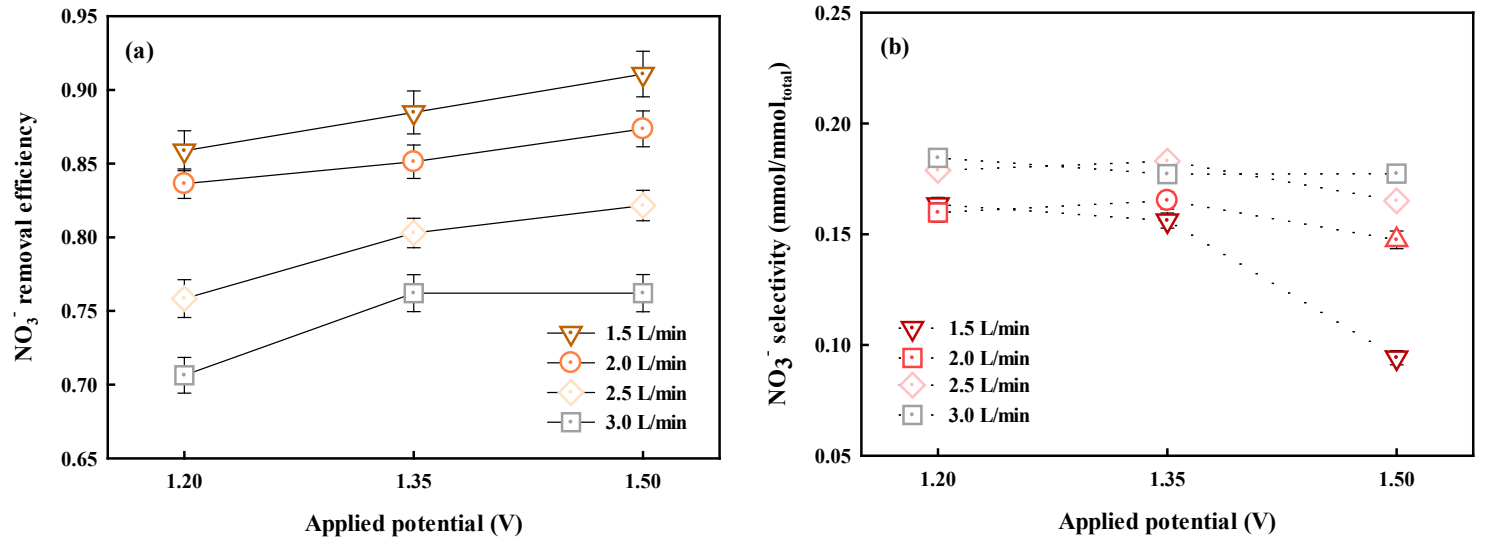

FIGURE 7. (a) Removal efficiency and (b) selectivity of $\mathrm{NO}_{3}{ }^{-}$at different potentials and flow rates. 
The results elicited in Fig. 7(a) implied that a larger applied voltage and a lower flow rate contributed to a reduced permeate $\mathrm{NO}_{3}{ }^{-}$concentration. The removal efficiency of $\mathrm{NO}_{3}{ }^{-}$ reached up to $91.08 \%$ at a flow rate of $1.5 \mathrm{~L} / \mathrm{min}$ and at an applied potential of $1.5 \mathrm{~V}$. In single-pass operation, a lower flow rate is preferred to provide sufficient contact time for better electrosorption of the ions in wastewater.

As shown in Fig. 7(b), the selectivity of $\mathrm{NO}_{3}{ }^{-}$was worsened by raising the potential and lowering the flow rate, thereby showing an inverse trend with the $\mathrm{NO}_{3}{ }^{-}$removal efficiency. In contrast with the earlier batch-mode studies, which showed that the flow rate barely affected the preferential adsorption, the $\mathrm{NO}_{3}{ }^{-}$selectivity slightly decreased at lower flow rates in our single-pass tests [42]. This was likely due to the fact that increasing the flow rate gave rise to shorter time for saturation of the electrode, and the adsorbed ions, such as $\mathrm{Cl}^{-}$and $\mathrm{SO}_{4}{ }^{2-}$, were quickly replaced by the supplemented $\mathrm{NO}_{3}{ }^{-}$from the continually supplied feed stream owing to its high affinity to the carbon electrode. This was also supported by our results in Fig. 6(b). As the space of the carbon electrode surface becomes saturated with ions in longer operations, $\mathrm{NO}_{3}{ }^{-}$tends to replace the other ions that have been already adsorbed by the carbon surface [27, 29]. Yeo et al. (2013) and Kim et al. (2013) ascribed the worse selectivity of $\mathrm{NO}_{3}{ }^{-}$at higher voltages to a significant increase in the ion mobilities of $\mathrm{Cl}^{-}$and $\mathrm{SO}_{4}{ }^{2-}$ through the AEM compared to that of $\mathrm{NO}_{3}{ }^{-}[36,43]$. Therefore, $\mathrm{NO}_{3}{ }^{-}$passes through the ionselective layer slower than the other anions at higher voltages, and consequently less ions are adsorbed on the electrode surface. Therefore, it could be concluded that applying a lower potential and supplying feed water at a faster rate are recommended to enhance the removal selectivity of $\mathrm{NO}_{3}{ }^{-}$with low energy consumption, which is one of the most problematic ionic species in wastewater, especially if high total ion removal is not necessary for reusing the wastewater.

\subsection{Successive operation of the pilot-scale MCDI system in a $15 \mathrm{~d}$ period}

A long-term operation of the pilot-scale MCDI system was conducted to assess the effect of organic and inorganic contaminants present in wastewater, which potentially risk the sustainability of the wastewater reuse process by exacerbating the electrode's performance. Several studies investigated the fouling and scaling issues by considering the fact that CDI and MCDI are being extensively used in practice [44]. A significant reduction in the ion 
removal efficiency in CDI was observed when the TOC concentration was increased up to 3.1 $\mathrm{mg} / \mathrm{L}$ [45]. The high organic loads in the brackish water led to the accumulation of organic matters within the pores of the carbon electrode, which was not able to be detached, thereby leading to a lowered energy efficiency of the system. Zhang et al. (2013) carried out a $15 \mathrm{~d}$ CDI pilot operation and confirmed the physical adsorption of organic compounds at $2 \mathrm{mg} / \mathrm{L}$ of dissolved organic carbon (DOC), which caused a greater reduction in the salinity removal efficiency [46]. IEMs provided a protective function for electrodes from the physical adsorption of organic substances in the MCDI system by shifting the fouling potential from the electrode to the IEM [47]. In the MCDI system, the negatively charged nature of organic matters migrated toward the IEM, partially accumulated on the membrane surface, and hence raised its electrical resistivity and gradually hampered the salt sorption performance.

However, unlike the earlier findings, the degradation of electrosorption caused by the organic compounds involved in the wastewater effluent was insignificant during the $15 \mathrm{~d}$ operation period (Fig. 8). As shown in Fig. 9, the negatively charged organic compounds in the wastewater effluent were fairly adsorbed on the electrode surface during electrosorption (29.1\%). However, the conductivity profile in the $15 \mathrm{~d}$ operation showed no significant degradation in the electrosorption/regeneration performance even though the organic loads in the wastewater were very high $(12.4 \mathrm{mg} / \mathrm{L} \mathrm{DOC})$. These results implied that the electrochemically adsorbed organic species were well discharged during the regeneration stage, thereby leading to sustainable operation of the MCDI for wastewater reuse. 


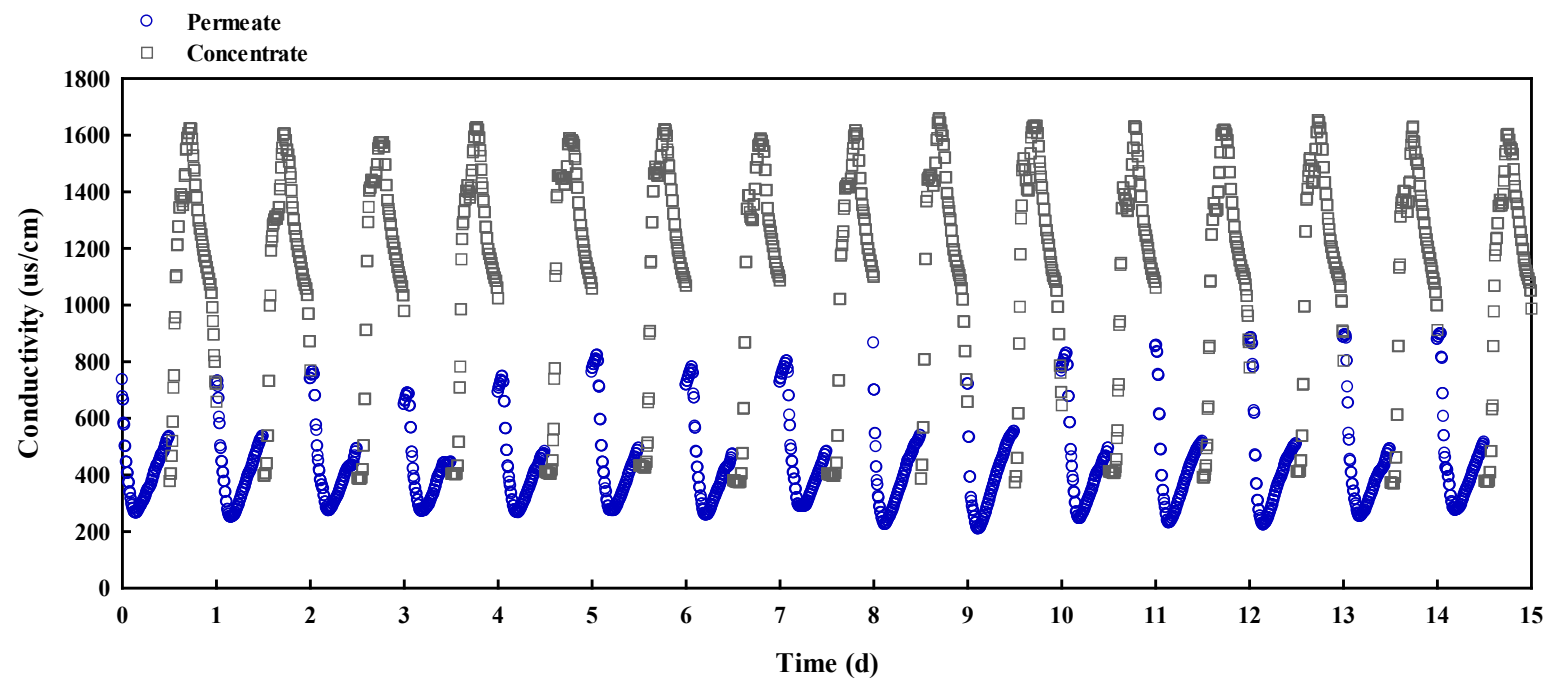

FIGURE 8. Average conductivity profile of the permeate (blue) and concentrate (gray) for 2min adsorption/desorption cycles on each day. The long-term MCDI operation was carried out for a period of $15 \mathrm{~d}$.

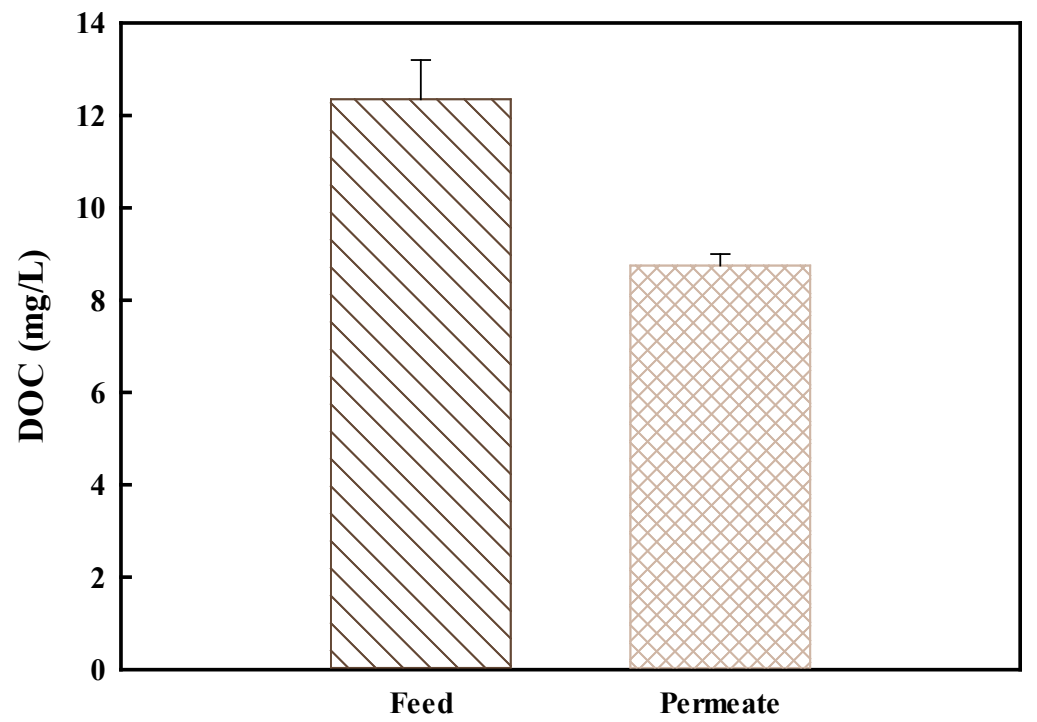

FIGURE 9. Removal of DOC from the feed and permeate of the wastewater.

The fouling-free MCDI operation could be partially explained by the roughness of the ion-selective electrodes used in the pilot-scale system. In general, the roughness of the IEM and carbon electrode surfaces is a significant factor affecting severe physical adsorption and accumulation of organics [48]. The root-mean-square roughness values of the activated 
carbon electrode and AEM in the conventional MCDI configuration were 756 and $159 \mathrm{~nm}$, respectively, whereas that of the surface of the anion-selective electrode tested in the pilot-run was $36 \mathrm{~nm}$ (Fig. 10) [49]. The flat surface of the coated layer offered a smaller opportunity for the organic particles to attach on the surface, thereby leading to less accumulation of the negatively charged organic species. Apart from the roughness, it was noted that the other surface properties of the IEM and electrode surfaces, such as the surface charge and hydrophobicity, also influenced the accumulation of organic species, which must be further studied for an in-depth discussion of the fouling-free surface of the anion-selective carbon electrode [50].

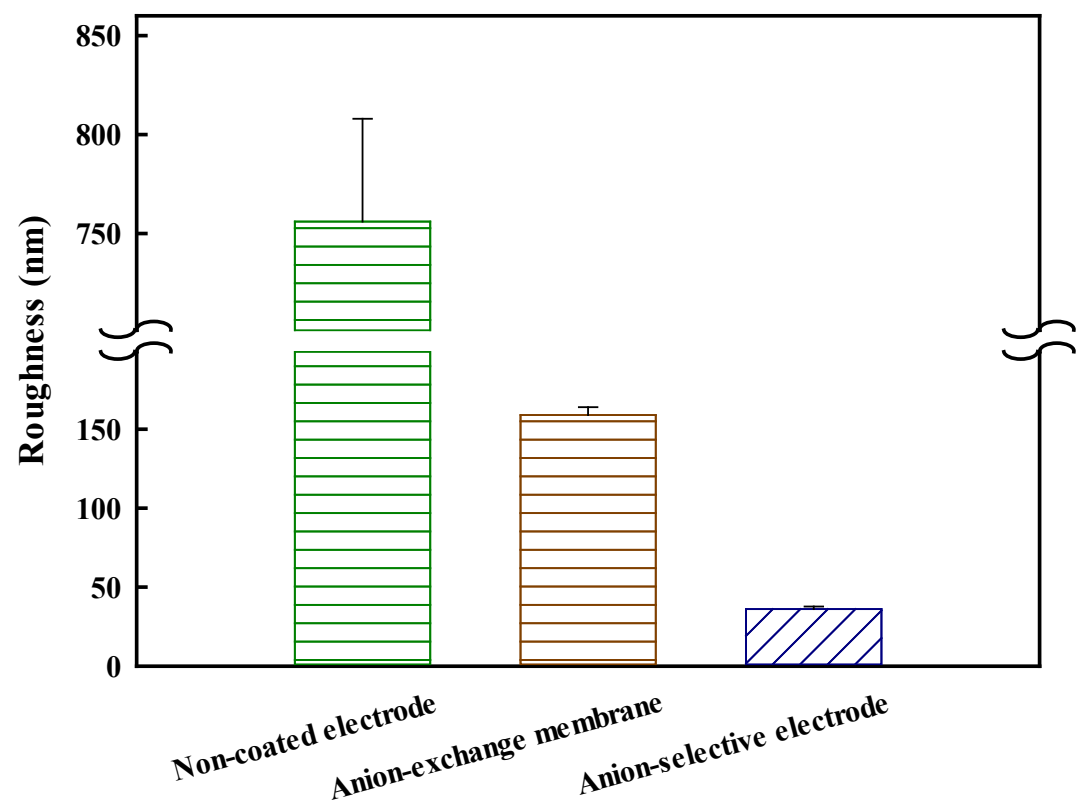

FIGURE 10. Root-mean-square roughness of the originally activated carbon electrode, AEM (Neosepta AMX), and anion-selective electrode.

\section{Conclusions}

Our work systematically explored MCDI for the demonstration of its practical use in wastewater reclamation at a pilot-scale using real wastewater effluent. The electrosorptive performance of electrodes, removal of charged species from wastewater, influence of 
operating conditions on ion removal, such as for $\mathrm{NO}_{3}{ }^{-}$, and performance degradation in longterm operations were investigated in this study.

The lab-scale tests confirmed rapid electrosorption and better SAC and charge efficiency of the ion-selective polymer-coated electrode. In a more practical view, installing the wastewater reuse system is expected to be more space-efficient by using the thin coated electrode rather than the conventional MCDI configuration, which as attributed to the high packing density of the electrodes in the module. The removal efficiency of the major anions from municipal wastewater via the pilot-scale MCDI unit was in the order of $\mathrm{Cl}^{-}>\mathrm{NO}_{3}{ }^{-}>\mathrm{SO}_{4}{ }^{2-}$, thereby showing high removal of $\mathrm{NO}_{3}{ }^{-}$, which is one of the most problematic ionic species in wastewater. The preferential anion removal was likely determined by the anion permselectivity through the AEM, which was dependent on the affinity of the anions to the membrane and on the change in the ion mobility through the AEM. The selectivity of $\mathrm{NO}_{3}{ }^{-}$could be enhanced in longer operations as it replaces the other anions adsorbed on the electrode. Supplying water at higher flow rates led to faster saturation of the electrode, and resulted in the swift replacement of $\mathrm{Cl}^{-}$and $\mathrm{SO}_{4}{ }^{2-}$ by the fast supply of $\mathrm{NO}_{3}{ }^{-}$from the wastewater feed. However, increasing the voltage worsened its selectivity owing to the significantly increased ion mobility of $\mathrm{Cl}^{-}$and $\mathrm{SO}_{4}{ }^{2-}$ through the AEM. The deterioration of MCDI performance caused by the contaminants present in the wastewater was insignificant during the $15 \mathrm{~d}$ pilot-scale operation. The smooth morphology of the ionselective electrode surface contributed to sustainable wastewater reuse in the long-term CDI operation by providing a small effective area for the physical accumulation of organic substances.

To sum up, the results from our study demonstrated that wastewater could be well reclaimed by achieving selective removal of the un-welcoming impurities. It was also shown that sustainable operation of MCDI in the long-term can be realized owing to the fouling-free properties of the ion-selective electrodes.

\section{Acknowledgements}

This work was supported by Korea Environment Industry \& Technology Institute (KEITI) through Industrial Facilities \& Infrastructure Research Program, funded by Korea Ministry of Environment (MOE) (RE201901117). 


\section{References}

[1] R. Connor, The United Nations world water development report 2015: Water for a sustainable world, The United Nations World Water Development Report, 2015.

[2] R. Connor, The United Nations world water development report 2017. Wastewater: The untapped resource, The United Nations World Water Development Report, 2017.

[3] D. Bixio, C. Thoeye, T. Wintgens, A. Ravazzini, V. Miska, M. Muston, H. Chikurel, A. Aharoni, D. Joksimovic, T. Melin, Water reclamation and reuse: implementation and management issues, Desalination, 218 (2008) 13-23.

[4] The United Nations, Transforming our world: The 2030 agenda for sustainable development, The United Nations, (2015).

[5] D. Batstone, T. Hülsen, C. Mehta, J. Keller, Platforms for energy and nutrient recovery from domestic wastewater: A review, Chemosphere, 140 (2015) 2-11.

[6] G. Gwak, D.I. Kim, S. Hong, New industrial application of forward osmosis (FO):

Precious metal recovery from printed circuit board (PCB) plant wastewater, J. Membr. Sci., 552 (2018) 234-242.

[7] G. Gwak, D.I. Kim, J. Kim, M. Zhan, S. Hong, An integrated system for CO2 capture and water treatment by forward osmosis driven by an amine-based draw solution, J. Membr. Sci., 581 (2019) 9-17.

[8] J. Ruiz, P. Álvarez-Díaz, Z. Arbib, C. Garrido-Pérez, J. Barragán, J. Perales, Performance of a flat panel reactor in the continuous culture of microalgae in urban wastewater: prediction from a batch experiment, Bioresour. Technol., 127 (2013) 456-463.

[9] S. Porada, R. Zhao, A. Van Der Wal, V. Presser, P. Biesheuvel, Review on the science and technology of water desalination by capacitive deionization, Prog. Mater. Sci., 58 (2013) 1388-1442.

[10] M.A. Anderson, A.L. Cudero, J. Palma, Capacitive deionization as an electrochemical means of saving energy and delivering clean water. Comparison to present desalination practices: Will it compete?, Electrochim. Acta, 55 (2010) 3845-3856.

[11] Y. Liu, C. Nie, X. Liu, X. Xu, Z. Sun, L. Pan, Review on carbon-based composite materials for capacitive deionization, RSC Adv., 5 (2015) 15205-15225.

[12] C. Hu, J. Dong, T. Wang, R. Liu, H. Liu, J. Qu, Nitrate electro-sorption/reduction in capacitive deionization using a novel $\mathrm{Pd} / \mathrm{NiAl}$-layered metal oxide film electrode, Chem. Eng. J., 335 (2018) 475-482.

[13] E. García-Quismondo, C. Santos, J. Palma, M.A. Anderson, On the challenge of developing wastewater treatment processes: capacitive deionization, Desalin. Water Treat., 57 (2016) 2315-2324.

[14] P. Liang, L. Yuan, X. Yang, S. Zhou, X. Huang, Coupling ion-exchangers with inexpensive activated carbon fiber electrodes to enhance the performance of capacitive deionization cells for domestic wastewater desalination, Water Res., 47 (2013) 2523-2530.

[15] C. Wang, H. Song, Q. Zhang, B. Wang, A. Li, Parameter optimization based on capacitive deionization for highly efficient desalination of domestic wastewater biotreated effluent and the fouled electrode regeneration, Desalination, 365 (2015) 407-415.

[16] J. Jiang, D.I. Kim, P. Dorji, S. Phuntsho, S. Hong, H.K. Shon, Phosphorus removal mechanisms from domestic wastewater by membrane capacitive deionization and system optimization for enhanced phosphate removal, Process Saf. Environ., 126 (2019) 44-52. [17] K. Fang, H. Gong, W. He, F. Peng, C. He, K. Wang, Recovering ammonia from municipal wastewater by flow-electrode capacitive deionization, Chem. Eng. J., 348 (2018) 301-309. 
[18] C. Feng, C.C. Tsai, C.Y. Ma, C.P. Yu, C.H. Hou, Integrating cost-effective microbial fuel cells and energy-efficient capacitive deionization for advanced domestic wastewater treatment, Chem. Eng. J., 330 (2017) 1-10.

[19] J.W. Palko, D.I. Oyarzun, B. Ha, M. Stadermann, J.G. Santiago, Nitrate removal from water using electrostatic regeneration of functionalized adsorbent, Chem. Eng. J., 334 (2018) 1289-1296.

[20] P. Dorji, J. Choi, D.I. Kim, S. Phuntsho, S. Hong, H.K. Shon, Membrane capacitive deionisation as an alternative to the 2 nd pass for seawater reverse osmosis desalination plant for bromide removal, Desalination, 433 (2018) 113-119.

[21] D.I. Kim, G. Gwak, P. Dorji, D. He, S. Phuntsho, S. Hong, H. Shon, Palladium Recovery through Membrane Capacitive Deionization from Metal Plating Wastewater, ACS Sustain. Chem. Eng., 6 (2017) 1692-1701.

[22] Y.J. Kim, J.H. Choi, Improvement of desalination efficiency in capacitive deionization using a carbon electrode coated with an ion-exchange polymer, Water Res., 44 (2010) 990996.

[23] J.Y. Lee, S.J. Seo, S.H. Yun, S.H. Moon, Preparation of ion exchanger layered electrodes for advanced membrane capacitive deionization (MCDI), Water Res., 45 (2011) 5375-5380.

[24] C. Kang, W. Li, L. Tan, H. Li, C. Wei, Y. Tang, Highly ordered metal ion imprinted mesoporous silica particles exhibiting specific recognition and fast adsorption kinetics, J. Mater. Chem. A, 1 (2013) 7147-7153.

[25] P. Biesheuvel, S. Porada, M. Levi, M.Z. Bazant, Attractive forces in microporous carbon electrodes for capacitive deionization, J. Solid State Electrochem., 18 (2014) 1365-1376.

[26] Y. Liu, L. Pan, X. Xu, T. Lu, Z. Sun, D.H. Chua, Enhanced desalination efficiency in modified membrane capacitive deionization by introducing ion-exchange polymers in carbon nanotubes electrodes, Electrochim. Acta, 130 (2014) 619-624.

[27] Z. Chen, H. Zhang, C. Wu, Y. Wang, W. Li, A study of electrosorption selectivity of anions by activated carbon electrodes in capacitive deionization, Desalination, 369 (2015) 4650 .

[28] C.H. Hou, C.Y. Huang, A comparative study of electrosorption selectivity of ions by activated carbon electrodes in capacitive deionization, Desalination, 314 (2013) 124-129.

[29] A. Hassanvand, G.Q. Chen, P.A. Webley, S.E. Kentish, A comparison of multicomponent electrosorption in capacitive deionization and membrane capacitive deionization, Water Res., 131 (2018) 100-109.

[30] W. Tang, D. He, C. Zhang, P. Kovalsky, T.D. Waite, Comparison of Faradaic reactions in capacitive deionization (CDI) and membrane capacitive deionization (MCDI) water treatment processes, Water Res., 120 (2017) 229-237.

[31] J. Yu, K. Jo, T. Kim, J. Lee, J. Yoon, Temporal and spatial distribution of pH in flowmode capacitive deionization and membrane capacitive deionization, Desalination, 439 (2018) 188-195.

[32] E. Nightingale Jr, Phenomenological theory of ion solvation. Effective radii of hydrated ions, J. Phys. Chem., 63 (1959) 1381-1387.

[33] C. Picioreanu, M. Van Loosdrecht, J. Heijnen, Modelling the effect of oxygen concentration on nitrite accumulation in a biofilm airlift suspension reactor, Water Sci. Technol., 36 (1997) 147-156.

[34] A. Poisson, A. Papaud, Diffusion coefficients of major ions in seawater, Marine Chem., 13 (1983) 265-280.

[35] Y. Li, C. Zhang, Y. Jiang, T.J. Wang, H. Wang, Effects of the hydration ratio on the 
electrosorption selectivity of ions during capacitive deionization, Desalination, 399 (2016) 171-177.

[36] J.H. Yeo, J.H. Choi, Enhancement of nitrate removal from a solution of mixed nitrate, chloride and sulfate ions using a nitrate-selective carbon electrode, Desalination, 320 (2013) $10-16$.

[37] W. Tang, D. He, C. Zhang, T.D. Waite, Optimization of sulfate removal from brackish water by membrane capacitive deionization (MCDI), Water Res., 121 (2017) 302-310.

[38] C.J. Gabelich, T.D. Tran, I.M. Suffet, Electrosorption of inorganic salts from aqueous solution using carbon aerogels, Environ. Sci. Technol., 36 (2002) 3010-3019.

[39] T. Sata, Studies on anion exchange membranes having permselectivity for specific anions in electrodialysis - effect of hydrophilicity of anion exchange membranes on permselectivity of anions, J. Membr. Sci., 167 (2000) 1-31.

[40] T. Luo, S. Abdu, M. Wessling, Selectivity of ion exchange membranes: A review, J. Membr. Sci., (2018).

[41] Q. Dong, X. Guo, X. Huang, L. Liu, R. Tallon, B. Taylor, J. Chen, Selective removal of lead ions through capacitive deionization: Role of ion-exchange membrane, Chem. Eng. J., 361 (2019) 1535-1542.

[42] J. Choi, H. Lee, S. Hong, Capacitive deionization (CDI) integrated with monovalent cation selective membrane for producing divalent cation-rich solution, Desalination, 400 (2016) 38-46.

[43] Y.J. Kim, J.H. Kim, J.H. Choi, Selective removal of nitrate ions by controlling the applied current in membrane capacitive deionization (MCDI), J. Membr. Sci., 429 (2013) 5257.

[44] P. Xu, J.E. Drewes, D. Heil, G. Wang, Treatment of brackish produced water using carbon aerogel-based capacitive deionization technology, Water Res., 42 (2008) 2605-2617. [45] M. Mossad, L. Zou, Study of fouling and scaling in capacitive deionisation by using dissolved organic and inorganic salts, J. Hazard. Mater., 244 (2013) 387-393.

[46] W. Zhang, M. Mossad, L. Zou, A study of the long-term operation of capacitive deionisation in inland brackish water desalination, Desalination, 320 (2013) 80-85.

[47] L. Chen, C. Wang, S. Liu, Q. Hu, L. Zhu, C. Cao, Investigation of the long-term desalination performance of membrane capacitive deionization at the presence of organic foulants, Chemosphere, 193 (2018) 989-997.

[48] Z. Zhao, S. Shi, H. Cao, B. Shan, Y. Sheng, Property characterization and mechanism analysis on organic fouling of structurally different anion exchange membranes in electrodialysis, Desalination, 428 (2018) 199-206.

[49] Z. Zhao, H. Cao, S. Shi, Y. Li, L. Yao, Characterization of anion exchange membrane modified by electrodeposition of polyelectrolyte containing different functional groups, Desalination, 386 (2016) 58-66.

[50] K. Xiao, X. Wang, X. Huang, T.D. Waite, X. Wen, Combined effect of membrane and foulant hydrophobicity and surface charge on adsorptive fouling during microfiltration, $\mathrm{J}$. Membr. Sci., 373 (2011) 140-151. 
TABLE 1. Average removal of ionic species in wastewater effluent during pilot-scale layered-MCDI operated at $1.2 \mathrm{~V}$ for $2 \mathrm{~min}$.

\begin{tabular}{|c|c|c|c|c|c|c|c|c|c|c|c|}
\hline \multirow[b]{2}{*}{ Ion } & \multirow[b]{2}{*}{ Unit } & \multicolumn{5}{|l|}{ Cations } & \multicolumn{5}{|l|}{ Anions } \\
\hline & & $\mathrm{Na}^{+}$ & $\overline{\mathrm{K}^{+}}$ & $\mathrm{Ca}^{2+}$ & $\mathrm{Mg}^{2+}$ & $\mathrm{NH}_{4}^{+}$ & $\mathrm{TP}$ & $\mathrm{NO}_{3}{ }^{-}$ & $\mathrm{NO}_{2}^{-}$ & $\mathrm{Cl}^{-}$ & $\mathrm{SO}_{4}^{2-}$ \\
\hline Feed concentration & $\mathrm{mM}$ & 4.08 & 0.46 & 0.27 & 0.15 & 0.007 & 0.03 & 0.76 & 0.003 & 2.26 & 0.46 \\
\hline Removal efficiency & $\%$ & 50.8 & 67.4 & 84.1 & 79.4 & 64.3 & 37.5 & 75.7 & 48.7 & 52.6 & 21.3 \\
\hline Adsorption capacity & $\mathrm{mmol} / \mathrm{g}$ & 0.3768 & 0.0309 & 0.0226 & 0.0120 & 0.0004 & 0.0010 & 0.0578 & 0.0001 & 0.1190 & 0.0098 \\
\hline
\end{tabular}

